\title{
Managing the Math Deluge: A Conversation with Edward Dunne
}

\section{Allyn Jackson}

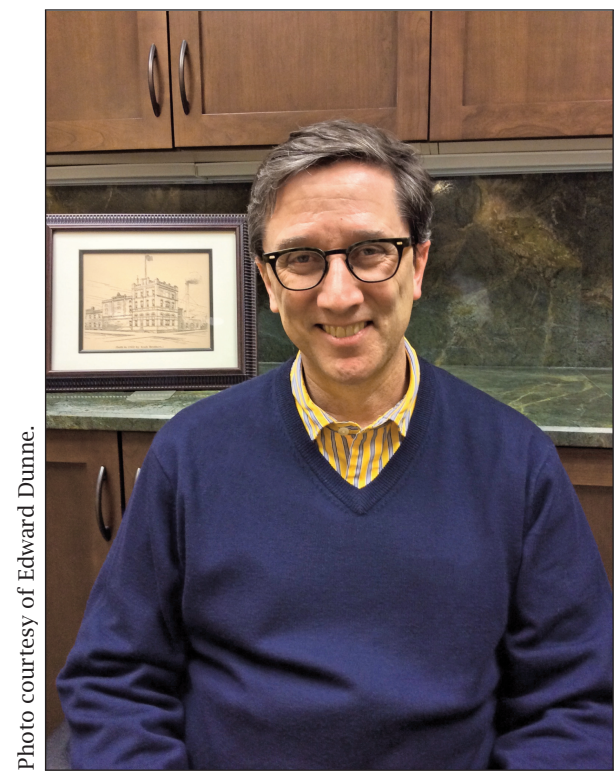

Edward Dunne.

In August 2014, Edward G. Dunne became ехесиtive editor of Mathematical Reviews (MR). He succeeded Graeme Fairweather, who had been in the post since 2008 and has now retired. Dunne is well known in the mathematical community for his work on the AMS book program: He was an AMS acquisitions editor for seventeen years before going to MR. He received his $\mathrm{PhD}$ in 1984 from Harvard University under the direction of Wilfried Schmid.

Before joining the AMS staff, Dunne held positions at Rice University, the University of Oxford, and Oklahoma State University and was an editor at Springer-Verlag for a year and a half. Late in 2014, the Notices talked to Dunne about the challenges his new position entails.

Notices: Why did you want to take the position at MR?

Dunne: I really love the mathematics literature. I would have been quite satisfied to continue working in the AMS publications group, but the love and respect I have for the mathematics literature gets to manifest itself in a different way through MR. Having that dedication to the literature will inform many of the decisions that need to be made in coming years so that MR continues to be a very useful tool.

For a long time MR has been at the forefront of a lot of changes in the way we get information. In

Allyn Jackson is senior writer and deputy editor of the Notices. Her email address is axj@ams . org.

DOI: http://dx.doi.org/10.1090/noti1249 the 1990s there was a change from viewing MR as a journal to viewing it as a database. That click in the mind-this is a database of information about the mathematics literature, not just a bound journalopened up an enormous number of possibilities. First the database was on tapes, then on CDs, and then, some years later, when the Internet became much more widely available, there were even more possibilities. No longer did you have to sit in front of a specific, dedicated computer to access the database and all the reviews; you could be anywhere on campus. That was another eye-opener. These were changes that were natural, and MR was right there at the very beginning.

A funny circumstance is that when I was at Springer, back in the early 1990s, one of the tasks I worked on was the digitization of what was then called Zentralblatt. So I have actually been involved in the database version of the competitor! That was one of the most enjoyable and rewarding aspects of my time at Springer. Through fate or good luck, an opportunity came along to do something similar again for the AMS, an organization I've been dedicated to for a long time.

Part of what makes MR work well is that it's run by people. We have-depending on how you count-seventy-five or eighty people working at the MR office in Ann Arbor, and there are more than seventeen thousand active reviewers. We are not just throwing more and more algorithms at the problem. By having people involved, MR can make authoritative statements about the literature, as opposed to programmed statements about the literature.

Notices: What are the main challenges you see for $M R$ ?

Dunne: The literature in mathematics, as well as all of the sciences, continues to grow at an insane rate. It's exponential growth. What MR does is to give people a sensible and efficient way of keeping track of what's going on in mathematics.

There is a temptation to rely on algorithmic, computational solutions. Some of that is fairly 
comfortable because it's familiar. You open up a Google window, you can search for restaurants or for unfamiliar terms that come up in conversationor for information about the mathematics literature. We need to make sure people understand that MR is better than that. We don't just run algorithms; there is actually thought and experience and talent behind what we do. We have to make sure that our technology is as good as possible. Technology changes very quickly. As soon as you catch up, technology takes another step forward. That challenge is not going to go away anytime soon, but it's an attractive challenge. Every time technology gets better, it's an opportunity for MR to get better.

Right now the AMS is running a strategic planning exercise that includes MR. The purpose is to think long and hard about where we want MR to be five years from now, in particular where we want MathSciNet to be. It's not just a casual thing. The AMS is dedicating serious resources to ensuring that we stay up to date and that we are a compelling resource for mathematicians.

Notices: Is there something about MR that the average mathematician typically doesn't know but ought to know?

Dunne: There are a few things. One is that there are seventy-five-plus people in the MR building who work tirelessly to get things right. For example, the author identification program is quite serious. When an author has a common name, like the name Wang for example, MR chases down which Wang it is, sometimes to the point of emailing the author to ask, "Are you the Wang who wrote the following five papers?" So when we say that a paper is by a particular mathematician, we are very sure that we have the right one. Reviews are copyedited, frequently twice and sometimes even four times. The attention to detail and the drive to get things right is really amazing. As a user of MR - which I have been for over thirty years-you just count on it being right, you count on it being useful. But it takes a lot of work, and seeing the people at MR do that work is really awe-inspiring.

Another thing is that there are search techniques or "tricks" you can do that the MR insiders know very well but that we don't always advertise well. If you poke around the MathSciNet website, you will find here and there some of this advice, but we need to do a better job of making sure that everybody can do what the insiders can.

There is also the Digital Mathematics Repository www.ams.org/dmr. Since we review more than 1,800 journals, we have lots of information about journals. Some years ago, we started offering on the Web a list of journals and links to their websites.

Notices: MR reviews more than 1,800 journals?
Dunne: Yes. Incredible, isn't it? And growing! Talk to me next year, and there might be another 50 or 100 new journals. Every month the editorial staff at MR meets and looks to see what new journals have come out and whether we should cover them.

We also watch out for journals that spring up that are in some sense illegitimate, so we keep a close track of the journals on Beall's list. Jeffrey Beall is a librarian at the University of Colorado who maintains a list of journals and publishers that have what he calls "predatory practices." Many of the journals on his list will publish anything you send them in return for a fee, say US\$1,000. MR tries to keep track of mathematics journals that might not be legitimate or are on shaky ground. That's another place where it's very helpful to have people involved. When we are deciding whether and how to cover a journal in MR or whether to drop coverage, it's a joint decision by people at MR who have mathematics research experience and people who have librarian experience-we have several people with advanced library science degrees. MR wants to cover only legitimate, refereed research journals so that there is something to be said for being a journal that is covered in MR.

Notices: What will be tough in your new job?

Dunne: One obvious thing that is going to be tough is keeping up with the flow of literature. Currently MR processes between 450 and 500 items per day. What this means is that we try to get about 480 items-a journal article, an article in conference proceedings, a book-into the system per day. An item will be cataloged; an editor will decide whether to send it to a reviewer; a review will be copyedited, processed, and added to the MSN database. At 480 per day, in an eight-hour day, that's 60 per hour or one per minute.

Notices: That's why you need all those people!

Dunne: That's right! That's a lot of mathematics. But we get it done, and we get it done every day of the week. Making sure that MR can keep up with the continuing increase in the literature is a big part of my job. At the same time, we have to make sure we can keep up with the changing expectations of users. Computing and the Web have become greater and greater parts of everyone's lives, in particular of the lives of scientists and mathematicians. Keeping up with the flow of literature and with changes in technology are going to dominate a lot of my time.

There is a lot of work to be done at MR every day, and it's a very busy place. It's also a lot of fun. I find it very rewarding to be immersed in a group of people who are very good at what they do and, without exception, enjoy what they are doing. It's a great place to be. 